\title{
Hydraulic Anatomy and Function of Trees-Basics and Critical Developments
}

\author{
Sebastian Pfautsch ${ }^{1}$
}

Published online: 7 October 2016

(C) Springer International Publishing AG 2016

\begin{abstract}
The study of hydraulic anatomy and function of trees has a long tradition. Motivated by current and projected changes in water availability, the field of tree hydraulics is experiencing a bout of activity. Significant progress has been made in understanding how water transport in trees is organized, how it integrates with other physiological processes, and what it takes for it to malfunction. Many of these advances have been possible, as fields of research that have traditionally been separate are merging, for example, wood anatomy and plant ecophysiology. These developments have led to the creation of powerful and novel approaches that help to answer longstanding questions relating to fundamental aspects of fluid transport in plants and how plants survive in the face of environmental stresses such as drought and freezing. The increased capacities to visualize the ultrastructures of wood in ever-greater detail and the ability for in-situ visualization of long-distance fluid transport have contributed to this progress. This review provides an entry point to the vast and continuously increasing knowledge of how water transport in trees is organized. It scales from cells to tissue anatomy to whole-tree physiology and landscape ecology. Known mechanisms and novel conceptual theories around how trees die as well as ways to prevent this fate are summarized. High-priority research questions for the coming years are formulated.
\end{abstract}

Keywords Xylem vessel $\cdot$ Pit membrane $\cdot$ Ray parenchyma . Cavitation resistance $\cdot$ Osmotic adjustment $\cdot$ Tree mortality . Wood anatomy

This article is part of the Topical Collection on Physiological Processes

Sebastian Pfautsch

s.pfautsch@westernsydney.edu.au

1 Hawkesbury Institute for the Environment, Western Sydney University, Locked Bag 1797, Penrith, NSW 2751, Australia

\section{Introduction}

Research into fluid transport dynamics in trees has certainly come a long way. Isaac Newton may have provided the initial catalyst in the 1660 s when he pondered the ascent of water in plant stems [1]. The history of botanical science shows that towards the end of the nineteenth century experts like Hermann v. Helmholtz, Eduard Strassburger, and Josef A. Böhm provided increasingly accurate descriptions of the physical processes involved in plant water transport. This development culminated in pioneering publications about the Cohesion Tension Theory (CTT) by Askenasy and Dixon and Joly in 1895 [2•]. The CTT explains how transmission of tension in water menisci is responsible for replacing water lost from leaves with water taken up from soil. This mechanism is now widely accepted as the basis of xylem water transport, even in the tallest trees, and it provides the platform for the current review.

Theoretical and empirical research in relevant fields continues to improve our understanding of how trees use water, transport metabolites, and transmit signals. As a result of predicted changes in the frequency and severity of drought due to global warming [3], research investigating the collapse of hydraulic functioning of trees has gained momentum [4]. In line with this research, we have generated an increasingly detailed knowledge of the hydraulic nexus between xylem and phloem, particularly the possible role of photosynthates in hydraulic functioning [5-7, 8••, 9]. In addition, we have progress in deciphering the role of stored water in stems [10], branches [11], and leaves [12] in keeping trees alive. Technological advances allow us to study in-situ fluid transport dynamics in trees - and also its collapse - at a previously unattainable level of detail $[13,14]$.

This review pays tribute to the complexity of anatomical structures essential for, and physical and physiological 
processes required to maintaining and regulating longdistance transport of fluids in trees and their effects on ecosystem functions and composition (Fig. 1). First, the anatomy of cells and tissues involved in long-distance fluid transport is described. Five segments that link structural traits with physiological functions of xylem water transport follow (i.e., specialized wood anatomy, hydraulic breakdown, tree mortality, integrated whole-tree hydraulic functioning, and the ecology of wood anatomy). Research in the field of tree hydraulics takes place at very different scales, which is reflected in this review that scales from descriptions of cell anatomy to elucidating the latest developments in tree- and landscape-scale models that improve our capacity to predict ecological consequences of water limitation. Along this journey, critical issues that require further research scrutiny are identified.

\section{Transport Tissues}

Long-distance transport of fluids in trees depends on a range of anatomical structures, cell types, and tissue systems, of which some are generic and others are more specific. Suberin-containing cells in the endodermal tissue of roots that form the Casparian strip are one example of a generic cell type that is shared across tree species and families. At the other end of the spectrum are cells and tissues that perform highly specialized tasks as part of fluid transport. Examples are tissue systems in leaves of certain angiosperms that facilitate 'guttation' (excretion of liquid water from leaf blades due to positive

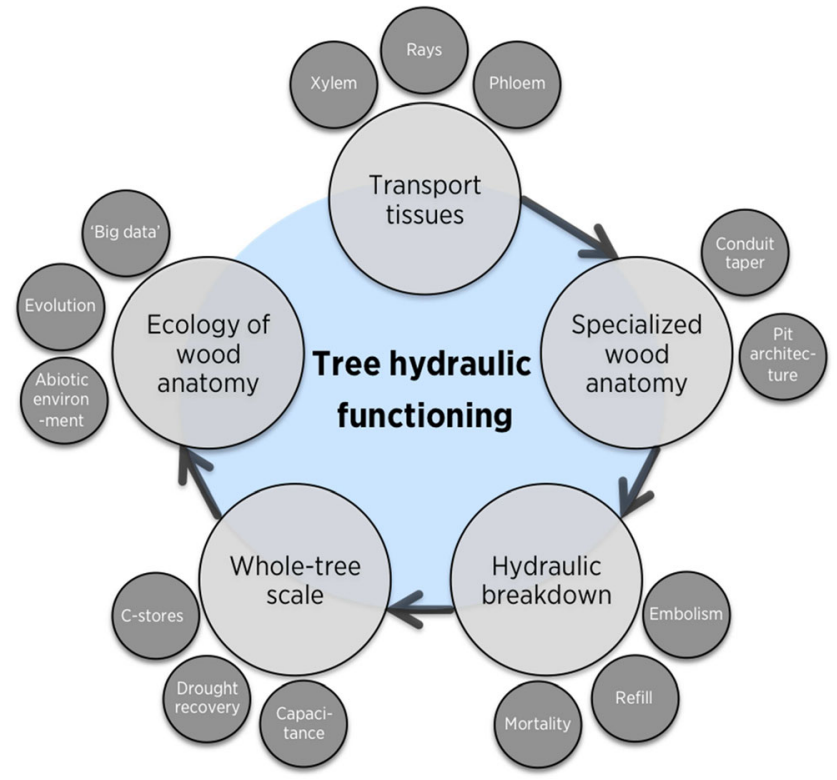

Fig. 1 Schematic outline of this review. Themes are placed around the central topic of tree hydraulic functioning. Themes scale along arrows from cells that make up xylem and other transport tissues to aspects related to landscape ecology. Small 'satellites' contain key words that will be addressed in the text of each of the five themes root pressure) or 'salt excretion' (as in mangroves). Although tissue systems for long-distance transport of water, metabolites, and signaling compounds may differ anatomically (Fig. 2a, b), their principal function is surprisingly similar and in nearly every tree stem, we will find secondary xylem, rays, and phloem.

\section{Secondary Xylem}

Secondary xylem is the water conducting tissue of sapwood and is produced by differentiation of fusiform initials located on the inner side of the vascular cambium. The development of fusiform initials into axial conduits has been demonstrated using model systems like Arabidopsis [15] or Zinnia [16]. Measuring gene expression in such systems has provided us with a welldeveloped picture of how cell elongation precedes modification of cell walls and lysis of the protoplast results in the empty conduit that forms the individual building block for vertical conduction of water. However, these study systems operate in vitro. As such, they are limited to collecting information on cell anatomy or 'omics' (e.g., proteomics, transcriptomics, etc.) that are unaffected by environmental drivers and the metabolic and hydraulic limitations induced by these drivers. We are thus left with a profound mechanistic understanding of how xylem is formed, yet, according to the theme of this review, this knowledge has yet to be translated into the context of forest and ecosystem functioning under varying environmental conditions.

Auxin, a plant hormone, plays a central role in the development of xylem [17-19]. The interested reader is referred to Hacke et al. [20] for a review on the role of auxin in primary and secondary growth, including formation of xylem. Auxin is synthesized in developing leaves before being transported downwards into the shoot and stem where it is involved in regulating cambial cell differentiation. This hormone represents the necessary biochemical link that facilitates an orchestrated and well-balanced development of leaves and stem sapwood.

According to the ontogenesis of both leaves and stem sapwood, the most recently developed leaves will be supplied with water by the most recently developed xylem. New or 'outer' xylem will support the proportion of the tree crown that experiences the highest rates of water loss due to exposure of the upper and outer crown to drivers of transpiration (e.g., vapor pressure deficit of the atmosphere, wind). With time and associated growth, the former top canopy becomes lower canopy; the former outer crown becomes inner crown. The cells and tissues associated with an aging canopy require progressively less water. Consequently, water transport in xylem supporting older portions of a tree declines and, ultimately, old xylem becomes obsolete and dysfunctional. At this stage, the transformation of sapwood to heartwood begins (Fig. 3a) where conduits become occluded (Fig. 3b). Cell occlusion occurs with deposition of gum or tyloses and will depend on the diameter of xylem vessels that are also referred to as conduits (i.e., narrow conduit = gum, 


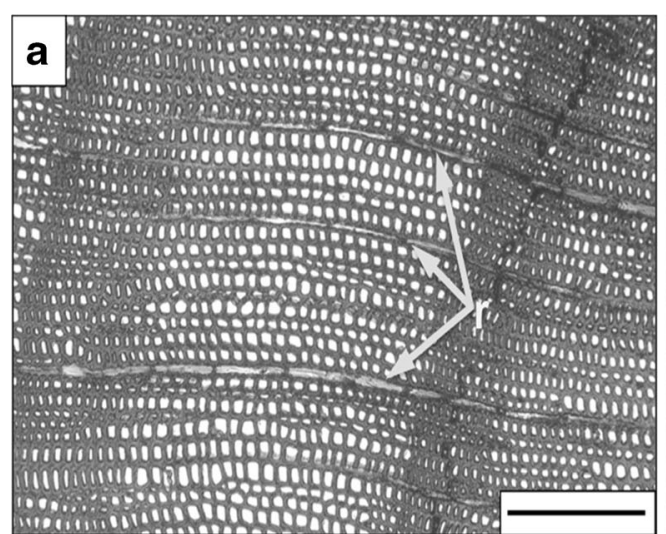

Fig. 2 Angiosperm and gymnosperm xylem. a Sapwood of Callitris oblonga showing changes in tracheid diameters due to seasonal variation; several unisereate rays $(r$, marked with gray arrows) are visible. b Diffuse porous sapwood of Eucalyptus regnans, containing

wider conduit $=$ tyloses $)[21,22]$. The result of aging processes throughout the tree canopy and associated progressive conduit occlusion leads to a radial profile featuring high rates of water transport in the outer xylem and low or no water transport in the inner xylem, and has been documented for both gymnosperm and angiosperm trees [23-26].

Although radial gradients of water transport in xylem are similar in gymnosperm and angiosperm trees, their xylem anatomy is not. Xylotomists have produced a considerable number of reviews regarding differences in anatomy as a result of phylogenetic divergence, the most recent by Carlquist [27] and Kedrov [28] (and see references therein). Put simply, 200 million years of evolution has resulted in separation of tissues for static support and water transport-from xylem in gymnosperms that consists only of tracheids for stability and vertical conductance of water (Fig. 2a), to xylem in angiosperms composed of fibers for stability and vessels for water transport (Fig. 2b).

\section{Wood Rays}

Wood rays are radially aligned files of specialized parenchyma cells (Fig. 4). Each ray cell originates from a ray initial located

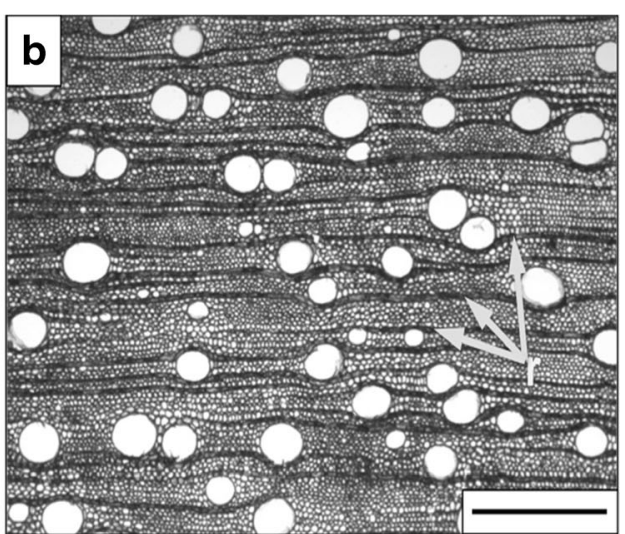

mostly solitary vessels of different diameters, embedded in a matrix of fibers and unisereate ray parenchyma. Images were produced using light microscopy. Scale bars: a $=500 \mu \mathrm{m}, \mathrm{b}=200 \mu \mathrm{m}$

in the vascular cambium from where cells are produced either to the outside (phloem-bound) or inside (xylem-bound) of the stem meristem. Each ray cell is a living unit, containing all of the necessary organelles and cytoplasm to function independently. The symplasts of adjacent ray cells are connected via plasmodesmata, forming a continuum that can functionally link xylem with phloem allowing radial bi-directional transport of water, solutes, and sometimes also pathogens $[8 \cdot \bullet$, 29-31]. In addition to transport, rays and the surrounding parenchymal tissue in sapwood also have important storage and remobilization functions. Seasonal dynamics of storage and remobilization of carbohydrates and amino-N metabolites in ray cells have been described [32-35]. However, empirical research into the role of rays in hydraulic functioning and associated loading, transporting, and unloading processes at short temporal scales (i.e., hours to days) is largely missing.

Recently, Pfautsch et al. [36•] visualized the flow path of water from phloem through rays into xylem by injection of fluorescent dyes. These experiments provided the first in-situ confirmation that the symplast of rays is indeed the main route for exchange of water between phloem and xylem in tree stems. Merging this and other empirical evidence $[8 \bullet \bullet, 37]$
Fig. 3 Effect of aging on sapwood. a Transition zone between conducting and nonconducting sapwood in E. regnans; vessels blocked by tyloses are clearly visible on the right side of the image. b Closeup of vessels in Robinia pseudoacacia blocked by tyloses. Images were produced using scanning electron microscopy (SEM). Scale bars: $\mathbf{a}=300 \mu \mathrm{m} ; \mathrm{b}$ $=200 \mu \mathrm{m}$
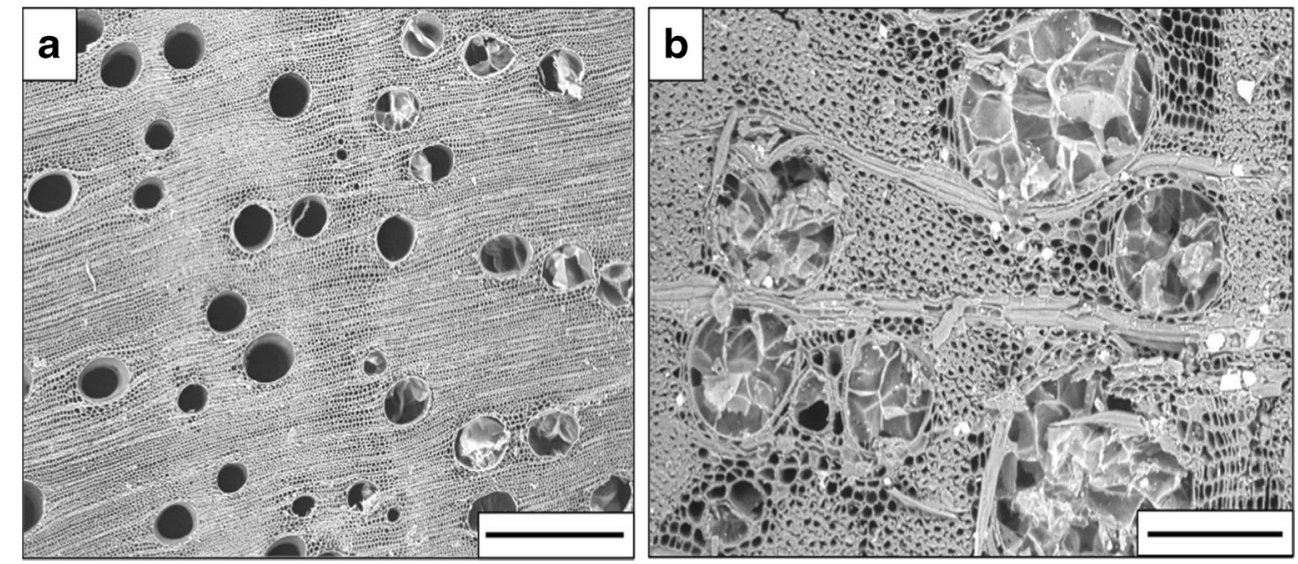

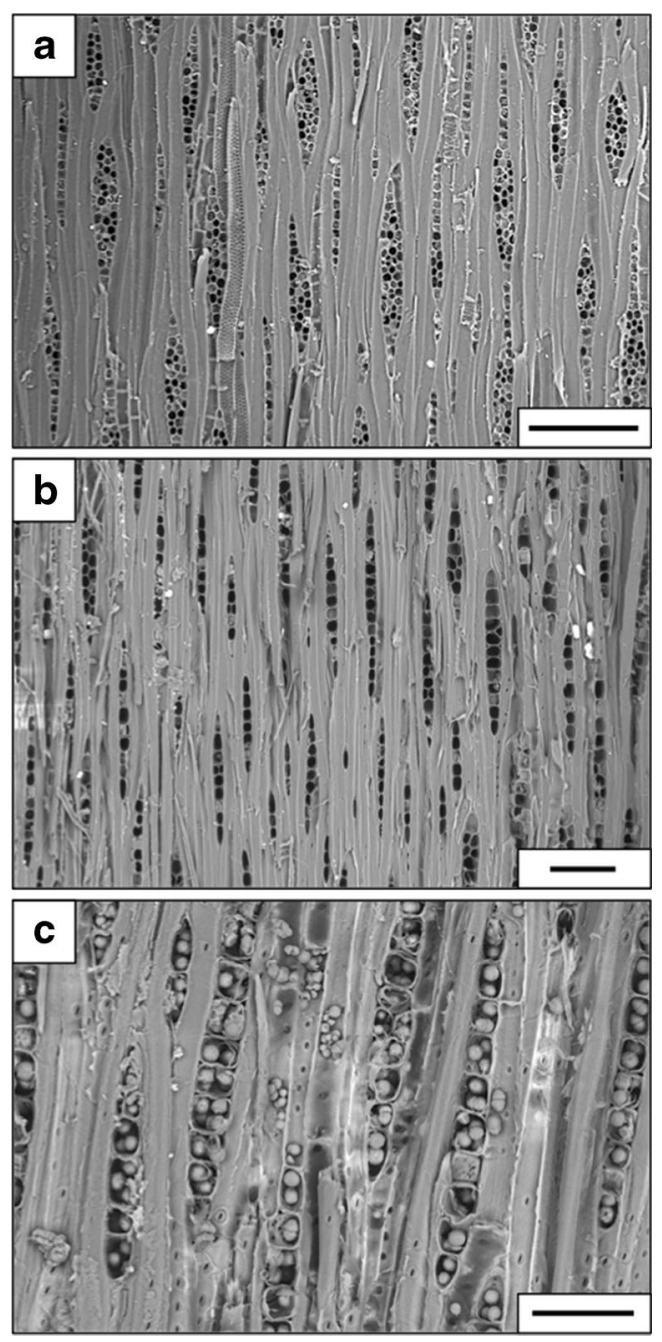

Fig. 4 Images of axial parenchyma and embedded radial wood rays in angiosperm sapwood (tangential view). a Walnut (Juglans regia) showing ray files that contain multiple rows of ray parenchyma. b, c, Forest red gum (Eucalyptus tereticornis) contains single-row ray files. Wood shown in $\mathbf{b}$ was extracted at $16 \mathrm{~m}$ tree height and rays did not contain starch granules. Wood shown in $\mathbf{c}$ originated from the base of the same tree and starch granules can be seen in high abundance in the rays. Images were taken using SEM. Scale bars: $\mathrm{a}=200 \mu \mathrm{m}, \mathrm{b}=100 \mu \mathrm{m}$, $\mathrm{c}=50 \mu \mathrm{m}$

with measurements of dynamic changes in stem diameters, as well as theoretical considerations about radial exchange of water and solutes between phloem and xylem [38, 39], has renewed interest in ray physiology [40]. As such, there is still much to be learnt about whole-tree hydraulic functioning that requires inclusion of rays as mediators between the two longdistance transport systems in tree stems.

\section{Phloem}

Compared to the anatomy of xylem and wood rays, phloem is a more complex tissue that is far more challenging to observe and manipulate experimentally. The latter is due to phloem cells being under positive pressure and the development of mechanisms to rapidly isolate injuries. As a result, invasive in-situ studies are difficult to implement $[8 \bullet \bullet, 41]$. Nevertheless, a recent compilation of research [42] highlights the diversity of phloem functions: assimilate transport, chemical and electrical signaling as well as plant defense. Based on our own research $[36 \bullet, 40]$ and that of our colleagues [8••, 37-39], whole-tree hydraulic regulation must be added to this list.

The cell types that make up phloem — sieve tube elements (ST) and companion cells (CC) - are considered to be alive at maturity although they are highly modified. For example, STs lack a nucleus and mitochondria, whereas CCs do contain these organelles and also encompass endoplasmatic reticula. Despite the lack of selected organelles, the close connection between STs and CCs by numerous plasmodesmata can compensate for the missing components and ensures full functionality of this heterogeneous tissue. For example, if CCs are missing, $\mathrm{O}_{2}$ and oxygen radicals can damage STs [43]. The cell wall anatomy of CCs can differ according to whether they are part of the collection, transport, or release phloem [44] to optimize their apoplastic and symplastic loading physiognomies. In contrast, the qualitative anatomy of STs remains independent of location. However, the position of STs may influence their abundance such that it is highest in transport phloem $[41,44,45]$. Transport phloem is found in veins and petioles of leaves as well as twigs, branches, stems, and coarse roots of trees, making it quantitatively the largest proportion of phloem [46]. Qualitatively, transport phloem has the most pronounced and measurable effect on tree hydraulic functioning as indicated by the increasing number of publications that utilize diurnal fluctuations in stem diameter to elucidate tree water relations $[37,40,47 \bullet \bullet, 48-50]$.

Cell walls of STs, CCs and, most importantly, phloem parenchyma in transport phloem remain un-lignified. This results in highly elastic cell walls, making this tissue ideal for water storage [51]. In most tree species, transport phloem is usually contained in a single layer of tissue, located on the outer side of the vascular cambium, underneath the periderm. As always, there is an exception to this general rule. Certain tree species found in water-limited environments, including those with high salinity, have been found to develop not a single, but multiple bands of transport phloem located within their sapwood $[52,53]$ underscoring the importance of transport phloem as water capacitor. How functions of, and processes in collection and release phloem impact tree water relations is less well understood.

\section{Specialized Wood Anatomy}

Water transport in trees is generally thought to be a passive process driven by the gradient in chemical potential of water in the rhizosphere and the atmosphere. This description is correct for the physical process that facilitates transpiration, 
but it does not take into account processes where trees need to actively invest energy to adjust hydraulic conductivity and limit cavitation (i.e., rupture) of water menisci. Up- and down-regulation of aquaporins according to availability of soil water is one example of investment of energy [54]. Modulating the activity of electrogenic proton pumps in guard cells to induce stomatal closure that will help preventing cavitation of conduits [55] is another example.

Besides immediate responses to water availability, trees can adjust their hydraulic system in response to long-term availability of water $[20,56]$. Selection processes have resulted in specialization of anatomical structures involved in water transport within species and along environmental gradients. To ensure long-term survival, trees must strike a balance between efficient and "safe" transport of water. Here we define efficiency as the hydraulic conductivity of the xylem tissue, or the rate at which water can be transported through the xylem at a given pressure gradient over a given distance. According to Hagen-Poisseuille's law of laminar flow, hydraulic conductivity in conduits increases with the fourth power of conduit diameter. Thus, small increases in conduit diameters translate to exponentially larger increases in hydraulic efficiency. However, wider conduits are also associated with a greater risk of embolism (gas bubble formation) caused by either freeze-thaw cycles or by water stress. This process has significant negative effects on water transport in trees and may result in canopy dieback and whole plant mortality [57]. While vulnerability to freeze-thaw-induced embolism is directly and positively linked to conduit diameter [58, 59], vulnerability to drought-induced embolism is primarily related to the architecture of intervessel pit membranes that facilitate transfer of water from one conduit to the next $[60 \bullet, 61]$.

\section{Conduit Taper}

According to Murray's Law [62], model vascular systems must strike a balance between construction costs and their capacity to conduct fluids. In tree stems, this balance is achieved through branching and taper of conduits, where conduits narrow and become more frequent with decreasing distance to the apex (i.e., pathlength effect). Conduit diameters may also become wider with increasing distance from the center of the stem (i.e., age effect). The influence of pathlength and age occur in tandem and both effects follow power functions, albeit they may not follow universal scaling exponents [63]. In addition, conduit diameters usually also widen with increasing water availability (i.e., environmental effect) as recently demonstrated for herbaceous [64] and woody species [56].

Pathlength effects on hydraulic functioning of xylem have been subject of many studies $[63,65,66]$. Taper of conduits results in maintenance of the equilibrium of hydraulic resistance to flow within the xylem network regardless of position along the flow path of xylem or phloem sap. In contrast to initial suggestions of continuous taper [67], it is now understood that taper is most pronounced in the apical region of tree stems and can even be absent or reversed in the basal section $[66,68]$. It is worth noting that conduit taper can result in more than $90 \%$ of the pathlength-associated total hydraulic resistance to sap flow being concentrated in branches that make up the first meter or so of pathlength just below the apex [66]. Acropetal taper of phloem STs has also been reported for shrubs [69]. Similar empirical assessments of hydraulic optimization in phloem architecture of trees are yet to be done.

Conduit taper is only one of many mechanisms used by trees to maintain homeostasis between water loss and water uptake, as optimal resource acquisition can be achieved by a number of trait combinations [70]. Importantly, conduit taper should not mistakenly be viewed as a 'rate-limiter' for water transport. It rather is a necessary adaptation to remain hydraulically functional when growing tall and poising the negative relationship between conduit diameter and hydraulic conductivity to reach maximum achievable rates of transpiration. Such rates are realized at intermediate xylem water potentials where the balance point between the driving force of transpiration (i.e., vapor pressure deficit of the atmosphere) and cavitation is struck. A global meta-analysis has shown that, under non-limiting conditions, trees generally reach these maximum rates of transpiration on a daily basis [71].

\section{Pit Architecture}

Xylem consists of a complex network in which embolism or vascular pathogens can be isolated while water transport continues in adjacent conduits. The functionality of this network depends to a large degree on bordered pits that connect vessels and allow the movement of water from one conduit to the next $[60 \cdot 61]$. Bordered pits consist of a secondary cell wall with a narrow aperture that flares into a wide pit chamber. This architecture maximizes both structural support provided by the secondary wall and the surface area available for transfer of water between conduits. In the center of each bordered pit is a partially hydrolyzed primary cell wall referred to as a pit membrane that separates one conduit from another. Pit membranes function as safety valves in the water transport system of plants. Their structure allows the free passage of water between cells but limits the spread of gas or pathogens through the xylem. The structure and function of pit membranes is therefore of critical importance for plants to persist in the face of abiotic and biotic stresses.

The structure of bordered pits and pit membranes must balance safety and efficiency in the hydraulic system of plants. Pit membrane pore size and thickness are key traits that determine this balance $[60 \bullet, 72,73]$. Wider pores in pit membranes translate to higher area specific pit hydraulic conductivity [74, 75]. However, wider pores will also allow gas to penetrate between conduits at lower xylem tensions, thus making the 
xylem more vulnerable to drought-induced embolism [74, 76]. The thickness of the pit membrane is also strongly related to vulnerability, with the thicker membrane occurring in species that are less vulnerable to embolism $[60 \bullet, 73]$. This relationship is most probably derived from the link between thickness and porosity and the resistance of thicker membranes to deflection and stretching. The diameter of the pit aperture is another important characteristic that impacts efficiency and safety; as pit aperture widens, hydraulic conductivity will increase but it will provide less support for pit membranes that are stretched between functional and embolised conduits.

Pit membrane structure differs markedly between angiosperms and gymnosperms [77]. In the vast majority of angiosperms, pit membranes are homogeneous in structure, with pores sizes distributed evenly across the membrane. Pores in homogeneous pit membranes are generally within a range of 5-20 nm in diameter, but some larger pores do occur rarely, and are of great importance to embolism resistance [78]. In many gymnosperms, particularly coniferous tree species, the pit membrane is divided into two functionally distinct zones. The outer area of the membrane (margo) has wide pores that allow for low resistance transfer of water between tracheids. The center of the membrane (torus) forms a thickened plug that blocks the pit aperture in the case that the tracheid becomes embolised. This design ensures low resistance of liquid transfer between tracheids while the protective function of the membrane is preserved by the thickened torus $[79,80]$.

\section{Hydraulic Breakdown}

\section{Mechanisms of Cavitation and Embolization}

Plants are capable of rapidly transporting water to heights in excess of $100 \mathrm{~m}$, and can extract water from extremely dry and highly saline soils. To achieve this, they have evolved a transport system that relies on water sustaining a tensile force, such that xylem sap is at negative absolute pressures [81-83]. However, this transport mechanism comes with its own set of problems, most notably that water under tension is prone to cavitation, which results in the formation of gas bubbles (embolism) [84]. Plants routinely face xylem tensions sufficient to cause cavitation and embolism, a problem exacerbated by environmental stresses such as drought, freezing, and salinity [85-87]. Embolism reduces the capacity of the xylem tissue to deliver water to sites of gas exchange and can therefore impact the ability of the plant to maintain a positive carbon balance. In the extreme, xylem embolism can reach lethal levels causing branch dieback and ultimately plant death with recent work suggesting that hydraulic traits play a central role in determining drought-induced mortality of trees in regional scale dieback [88-90].
The two principal environmental factors that lead to xylem embolism are drought and freeze-thaw cycles. While the ultimate cause of cavitation and embolism is tension present in the xylem sap, the physical mechanisms by which cavitation occur differs between drought and freezing stress. Below, an outline is provided that summarizes what is known about these mechanisms and how they relate to differences in xylem structure.

\section{Freeze-Thaw Induced Embolism}

Cycles of freezing and thawing are known to cause embolism in the xylem. Freezing of sap in the xylem is thought to cause gas bubble formation (gas segregation) due to the fact that gas is insoluble in ice $[57,91,92]$. During thawing, these bubbles may expand to form emboli if xylem pressures are sufficiently negative [93, 94]. This mechanism of embolism formation is of great importance to woody vegetation occurring in areas that experience subzero temperatures. The degree to which embolism occurs in xylem during freeze-thaw cycles has been related to a range of factors including the nadir temperature experienced [95], the number of cycles the plant is exposed to [86], and anatomy of the xylem [77]. A number of studies have shown a direct relationship between conduit diameter and vulnerability to freeze-thaw induced embolism, with wider conduits being consistently more vulnerable than narrow ones $[58,93,96,97]$. This relationship is present across species, with species that have a wider mean vessel diameter being more impacted by freeze-thaw events $[58,87,96,97]$. It is also apparent within a plant with wider earlywood or metaxylem vessels being more prone to freeze-thaw embolism than smaller vessels in the same xylem cross-section [59, 98]. The magnitude of xylem embolism accumulating over the winter period varies greatly between species, ranging from close to $100 \%$ in vines and ring porous tree species to almost zero in some conifers and evergreen angiosperms. Species that suffer extensive embolism during the winter generally have mechanisms to refill embolised vessels via root or stem pressure (e.g., grapevine and sugar maple), or rely on the growth of a new ring of wide earlywood vessels to sustain water transport in the spring (ring porous species).

\section{Drought-Induced Embolism}

As available soil moisture decreases, the amount of tension required for the plant to draw water from the soil and transport it to the canopy will increase. This increase in xylem sap tension will increase the probability of drought (water stress)-induced embolism formation and its spread. Cavitation in water at negative pressure is now a wellrecognized phenomenon. The nucleation of cavitation can occur via a number of mechanisms including homogeneous nucleation in the bulk phase or heterogeneous nucleation from 
hydrophobic surfaces or vapor embryo. In the xylem, cavitation is thought to occur primarily via heterogeneous nucleation from gas nuclei that are drawn through inter-conduit pit membranes. This process is known as 'air seeding' and is dependent on the structure of bordered pits and pit membranes [99]. The air-seeding hypothesis is supported by experimental evidence from a range of techniques [100, 101], correlations between pit membrane structure and vulnerability to embolism $[60 \bullet, 73]$, and by direct visualization of embolism spread between conduits $[102,103]$.

Plant species vary dramatically in their susceptibility to drought-induced embolism, dependent in variation in their xylem structure. This trait, known variously as cavitation resistance, vulnerability to embolism, or embolism resistance, has emerged as a key ecological trait that drives the distribution of plant species across gradients of water availability. It is most commonly defined by the level of water stress (xylem water potential) that causes a $50 \%$ loss of hydraulic conductivity in the stem, leaf, or root being measured $\left(P_{50}\right)$. The $P_{50}$ of plants declines (becomes more negative) with mean annual rainfall, although variation is greatly increased at the drier end of this scale because of drought avoidance strategies employed by the species growing in arid environments, e.g., drought deciduousness. The relationship between $P_{50}$ and the seasonal minimum water potential experienced by the plant in the field $\left(P_{\min }\right)$ is much less variable, indicating that embolism resistance is tightly coupled with the level of water stress that a particular species can withstand.

\section{Visualizing Cavitation}

Measurements of vulnerability to embolism are most commonly made using bench-top techniques based on observed reduction in hydraulic conductivity, as the plant sample is dehydrated. This includes bench dehydration, air injection, and centrifuge-based techniques. A thorough comparison of these techniques is given in Cochard et al. [104] and will not be covered in detail here. More recently, a range of noninvasive imaging techniques have been utilized to visualize the xylem function in living intact plants. The majority of these observations have been undertaken with magnetic resonance imaging (MRI) and computed microtomography (microCT) although other techniques such as neutron radiography have also been employed. These techniques allow in-situ observations of xylem function at unprecedented resolution while avoiding potential artifacts that may be associated with destructive sampling and measurement protocols $[105,106]$.

For observations of intact plants, MRI is limited to a spatial resolution of around $40 \mu \mathrm{m}$ per pixel, which generally constrains observations to species with very wide xylem vessels $[107,108]$. MicroCT can attain much higher spatial resolutions and has been particularly effective when derived from synchrotron radiation $[109,110]$. High-resolution imaging has helped to confirm that air seeding through pit membranes is the primary mechanism by which cavitation occurs in both angiosperms and gymnosperms $[13,102,111]$. In-situ high-resolution imaging of plant hydraulic functions can assist in resolving questions about the evolution and reversal of vascular cavitation. However, no imaging technique represents the holy grail of plant hydraulics. Putative limitations cannot be ignored. Direct translation of digital images to conductivity of vessel networks remains problematic, in part as a result of vessel connectivity. Furthermore, current applications can only image small specimens. We are still far away from imaging mature tree stems, and even further from doing this in the field, but see [112-114] for progress in this important direction.

\section{Tree Mortality}

Worldwide, forests represent the largest terrestrial sink for carbon dioxide and annually transpire $35 \times 10^{15} \mathrm{~L}$ water into the atmosphere. Thus, any drought-induced mortality of forests can significantly affect the global cycles of carbon and water, with additional feed-forward effects on rates of global warming. This information, together with (a) the realization how little is understood about the modus operandi of tree mortality [115, 116], and (b) predictions of environmental change in the twenty-first century has intensified research into why and how trees die $[7 \cdot, 117-122]$.

While there has been progress in understanding the cascading processes that lead to death of trees, it is worth noting how the terminology used in this field of research encourages the construction of novel terms. "Global-change-type drought" [123], "climate-driven forest die-off" [124] or most recently "massive conifer mortality" [125], and "megadisturbance" [126] may possibly help in selling the topic to the public and funding bodies, yet they do little to progress the field and associated scientific understanding. It could be argued that such terminology is necessary to raise political awareness of the problem, but only time will tell if that is true. The increasing availability of global databases and rapid progress in their analyses with sophisticated statistics and modeling has led researchers to extrapolate relatively local observations of forest mortality to a global scale $[125,127]$. Such broadsweeping approaches have been questioned [128]. Despite the indisputable value of such analyses, caution in the use of language should be taken to prevent another 'Waldsterbentype' fiasco as experienced in the 1980s [129].

Water stress must be lethal to induce hydraulic failure in trees (i.e., irreversible desiccation of tissues) and their subsequent death. Such an outcome is most likely produced by exceptional droughts [130]. However, different types of drought exist [131•] and chronically stressed individuals and stands may be pushed beyond their point of resilience even under relatively mild soil water deficits (i.e., weeks to months 
compared to years) or unusually high atmospheric demand for water (hours to days). These considerations lead to a core problem for the entire field: how can we reliably define the limit of tolerance of a given species, which once crossed, will irreversibly lead to mortality? This boundary will change for different species, ontogenetic stage, accumulated chronic stress, and time of year. A second question is how do we define if this line has been crossed because of drought or pathogen or insect attack prior to, during or after a tree experienced water stress? Other responses must also be taken into account: intra- and interspecific variation may propel or slow down their stress response [132••]; trees that have lost their entire canopy as consequence of drought can resprout under more favorable conditions [133]; extreme climate events such as heatwaves may [134] or may not [135••] result in tree mortality. The list goes on.

For the last two decades, the field of tree hydraulics has wrestled with a range of concepts to explain survival of trees during drought including (1) percentage loss of conductivity $\left(P_{12}=\right.$ loss of $12 \%, P_{50}=$ loss of $50 \%, P_{88}=$ loss of $88 \%$ conductivity), (2) isohydry versus anisohydry, and (3) hydraulic failure versus carbon starvation. While these concepts have helped to progress the field, none has been crowned as paragon similar to CTT. The literature describing the pros and cons of these theories is vast and will not be discussed here. More recently, a number of new concepts have surfaced that take a fresh approach to the old problem. Three of these concepts that extend from species to landscape are introduced here.

The first concept suggests a species-specific approach using measurements of plant hydraulics, tissue characteristics, and branch specific leaf area [11]. This work [11] introduced a theoretical framework around the empirical assessment of the time $\left(T_{\text {crit }}\right)$ it takes for a foliated branch to reach critical levels of desiccation following stomatal closure. The novelty of the concept lies in assessing stomatal and cuticular "leakiness" combined with quantification of capacitive water stores that can shorten or prolong $T_{\text {crit }}$. The second concept combines stomatal regulation strategies with characteristics of xylem vulnerability to explain differences in drought response of co-occurring plant species [136]. While using the traditional framework of isohydric-anisohydric regulation of plant water status, Skelton and colleagues expanded this framework by including additional traits $\left(P_{\mathrm{x}}, P_{12}, P_{50}, P_{88}\right)$ that relate to the tolerance of loss of conductivity. The third concept explores a holistic approach by translating multi-year rainfall deficits into tree mortality across large tracts of land [131•]. The most significant contribution of this concept is the recognition how events of meteorological drought, shifts in the seasonality of rainfall, and associated build-up of soil water deficits are required to culminate in regional tree mortality. One of the most important tasks for future research about tree mortality is to approach these novel concepts with empirical data to verify their relevance.

\section{Integrated Whole-Tree Hydraulic Functioning}

Describing the process of tree mortality is ideal for demonstrating what integrated whole-tree hydraulic functioning stands for. Mortality starts with the collapse of communication between discrete processes at the molecular level. This triggers negative effects on biochemical functioning, causing declining organization within cells, leading to tissue damage. If repair of functionality at any of these levels is not possible, the propagation of dysfunctions will lead to death of the entire tree. Several levels of organization need to be combined to explain the response of an entire organism.

Scaling in any system is a logical process. For tree functioning, scaling results in a holistic understanding of a range of processes, given that an appropriate level of complexity can be retained. Current research in tree hydraulics aims to integrate a wide range of traits and processes that regulate fluid transport at the organism scale. Some of this research is concerned with the capacitive use of water and its effects on whole-tree functioning. For example, Gleason and colleagues [137] used excised apical shoots to investigate which combination of hydraulic traits was most successful in extending the time before $50 \%$ loss of leaf conductivity occurred. Their investigation found that shoots of species from arid environments expressed a greater capacity to prolong dry down to critical levels of water stress compared to shoots from species growing in mesic conditions. However, the study revealed that none of the individual hydraulic traits responsible for this observation (namely $W_{\Psi}, P_{50 \mathrm{~L}}$, and $W_{\text {Time }}$ ) were traded off against each other. The authors concluded that the capacity of trees to withstand desiccation is more than just a product of a combination of hydraulic traits but involves other ecological strategies.

One possible ecological strategy could be the capacity for 'hydraulic priming' (sensu [138]) where targeted cell functions are up- or down-regulated in the presence of declining water potentials. Here, the capacity to remobilize carbohydrates from storage may play a critical role [139] further supporting the notion that, ultimately, the functionality of water transport in xylem is coupled with carbohydrate transport in phloem [9, 40]. In theory, this link is well described [38, $140]$, yet in practice we lack studies that combine in-situ measurements of pressure and concentration gradients driving radial transport of water and carbohydrates.

It was mentioned earlier that the life history of trees can play a critical role in the capacity to cope with water limitation. A recent study, using saplings of Pinus, reported large hydraulic and chemical differences among individuals impacting their capacity to survive water limitation [6]. While attention to interspecific differences in hydraulic and chemical traits is crucial when selecting 'future-ready' genotypes of individual species [141], it is also important to note that hydraulic and chemical signals vary in their response to 
water limitation according to position within a tree. The effect of such variation leads to hydraulic segmentation where organs involved in water transport differ in their vulnerability to water limitation. Segmentation has been shown for olive trees where leaves and roots were much more vulnerable to water limitation than stems and branches [142]. The same study also assessed how well the different organs recovered from drought. This is an important and understudied aspect, as not all droughts lead to mortality. To date, we rarely focus on documenting the capacity of trees to recover from water limitation and to assess the long-term effects on productivity and biochemistry. Given the predicted changes in rainfall frequency and amount due to climate change, negative impacts on native and planted forests via repeated, non-lethal drought events could have severe implications on the biogeochemical cycles of carbon, nutrients, and water.

\section{The Ecology of Wood Anatomy}

Research in the bisecting fields of ecology and wood anatomy aims to decipher how environmental drivers, such as latitude, longitude, and altitude, and also availability of soil water and nutrients, temperature, atmospheric $\mathrm{CO}_{2}$ concentrations, and climate extremes impact qualitative and quantitative traits of wood. Studies of ecological wood anatomy differ from those of functional or paleontological wood anatomy as the latter are often concerned with physical and biomechanical aspects [143] and evolutionary development of wood structures [144]. Ecological wood anatomy can be used to describe the impact of current biotic and abiotic agents on the ecology of woody plants and how they shape xylem and wood development. The literature is rich in reports of relationships between ecology and wood anatomy ranging from species-specific [145-147] and genera- and clade-specific [56, 148] to more general descriptions [27, 28, 149-153]. A clear separation between ecological, functional, and paleontological wood anatomy may not always be possible as demonstrated in the latest book on the topic [154].

For several decades, protagonists in the fields of wood anatomy, plant hydraulic functioning, silviculture, and ecology have collected data on anatomical and functional wood traits. Today, these data can be used for the development of 'big data' sources and global meta-analyses. Indeed, some global analyses have already emerged to shed light on the ecological drivers behind wood density [155] and the wood structure of angiosperms [156]. Initiatives like TRY [157], including the XFT database within TRY, and the InsideWood database [158] will be valuable in unveiling global patterns and trends of how changing environmental conditions can influence anatomy of wood.

\section{Conclusions}

Trees have evolved complex structures to distribute water and assimilate throughout their organs. Today, the field of plant hydraulic research uses a wide range of techniques to advance our understanding of the structures and processes involved in these transport systems. From century-old techniques such as light microscopy to the latest three-dimensional X-ray scanning methods and from field surveys to complex ecological modeling, plant hydraulic research is clearly interdisciplinary and multi-faceted, reflecting the incredible diversity we find among trees. This field of research has come of age.

Although substantial progress has been made in the past, the future of this exciting field of research lies in the many questions that still need answering, and the phenomena that need explaining. The tasks will involve better understanding of environmental impacts on genetic up- and/or downregulation of processes responsible for the construction of the transport networks in roots, stems, and leaves, and the inclusion of scaling to assess forest function under changing climates.

Pressing questions that need answering include the following:

- What are the anatomical pathways along which assimilates help regulate water transport and possibly assist in refilling?

- How can we increase the accuracy of predictions for tree mortality in the field?

- Why does plasticity in drought tolerance vary across cooccurring tree species?

- Can evolution of hydraulic traits keep pace with rapid changes in climate?

- Which forests are most vulnerable to these changes?

These are just a few of the many questions that will keep researchers busy today and into the future.

Acknowledgments The author would like to thank Brendan Choat, Peter Reich, and Mark Tjoelker for discussions and commentaries that greatly benefitted the scope and quality of this review. In addition, the fast turn-around and comments by an anonymous reviewer must be thanked for. The help of Tina Bell is acknowledged for editing and critical annotations on the final draft. Tim Murphy and Richard Wuhrer at the Advanced Materials Characterization Facility of Western Sydney University were instrumental for SEM imaging.

\section{Compliance with Ethical Standards}

Conflict of Interest Dr. Pfautsch has no conflicts of interest.

Human and Animal Rights and Informed Consent This article does not contain any studies with human or animal subjects performed by the author. 


\section{References}

Papers of particular interest, published recently, have been highlighted as:

- Of importance

•- Of major importance

1. Beerling DJ. Newton and the ascent of sap in plants. Nature Plants. 2015. doi:10.1038/NPLANTS2015.5.

2. Brown HR. The theory of the rise of sap in trees: some historical and conceptual remarks. Phys Perspect. 2013;15:320-58. A valuable source illuminating historic developments that led to today's understanding of plant hydraulics.

3. Dai A. Increasing drought under global warming in observations and models. Nat Clim Chang. 2012;3:52-8.

4. Sperry JS, Love DM. What plant hydraulics can tell us about responses to climate-change droughts. New Phytol. 2015;207:14-27.

5. Bloemen J, Vergeynst LL, Overleat-Michiels L, et al. How important is woody tissue photosynthesis in poplar during drought stress? Trees. 2016;30:63-72.

6. Garcia-Forner N, Sala A, Biel C, et al. Individual traits as determinants of time to death under extreme drought in Pinus sylvestris L. Tree Physiol. 2016. doi:10.1093/treephys/tpw040.

7. Mitchell P, O'Grady A, Tissue DT, et al. Drought response strategies define the relative contributions of hydraulic dysfunction and carbohydrate depletion during tree mortality. New Phytol. 2012;3:862-72. One of the few papers that report effects $\left(\mathrm{H}_{2} \mathrm{O}\right.$ - and $\mathrm{C}$-related) of a chronic water limitation ( $>200$ days) on angio- and gymnosperm species, revealing different strategies to cope with that limitation.

8.• Sevanto S, Hölttä T, Holbrook M. Effects of the hydraulic coupling between xylem and phloem on diurnal phloem diameter variation. Plant Cell Environ. 2011;34:690-703. A very clever approach was taken to manipulate radial conductance between phloem and xylem. The paper also contains a well-composed theory around the causes of stem diameter variation.

9. Sevanto S. Phloem transport and drought. JExp Bot. 2014;65:1751-9.

10. Anderegg WRL, Meinzer FC. Wood anatomy and plant hydraulics in a changing climate. In: Hacke U, editor. Functional and ecological wood anatomy. Springer: Switzerland; 2015. p. 235-53.

11. Blackman C, Pfautsch S, Choat B, et al. Toward an index of desiccation time to tree mortality under drought. Cell \& Environment: Plant; 2016. doi:10.1111/pce.12758.

12. Azuma W, Ishii HR, Kuroda K, et al. Function and structure of leaves contributing to increasing water storage with height in the tallest Cryptomeria japonica trees in Japan. Trees. 2016;30:141-52.

13. Choat B, Badel E, Burlett R, et al. Noninvasive measurement of vulnerability to drought-induced embolism by X-ray microtomography. Plant Physiol. 2016;170:273-82.

14. Melcher P. Seeing into the xylem using non-invasive techniques provides clarity in understanding mechanisms involved in long-distance sap transport in plants. Plant Cell Environ. 2015;38:2497-9.

15. Kubo M, Udagawa M, Nishikubo N, et al. Transcription switches for protoxylem and metaxylem vessel formation. Genes Dev. 2005;19:1855-60.

16. Demura T, Tashiro G, Horiguchi G, et al. Visualization by comprehensive microarray analysis of gene expression programs during transdifferentiation of mesophyll cells into xylem cells. Proc Natl Acad Sci. 2002;99:15794-9.

17. Berleth T, Mattsson J, Hardtke CS. Vascular continuity and auxin signals. Trends Plant Sci. 2000;5:387-93.

18. Fukuda H. Xylogenesis: initiations, progression, and cell death. Annual Review of Plant Physiology \& Plant Molecular Biology. 1996;47:299-325.
19. Yoshida S, Iwamoto K, Demura T, et al. Comprehensive analysis of the regulatory roles of auxin in early transdifferentiation into xylem cells. Plant Mol Biol. 2009;70:457-69.

20. Hacke U, Spicer R, Schreiber S, et al. An ecophysiological and developmental perspective on variation in vessel diameter. Plant, Cell and Environment. 2016. doi:10.111/pce.12777.

21. Bonsen KJM, Kučera LJ. Vessel occlusions in plants: morphological, functional and evolutionary aspects. IAWA Bulletin. 1990;11:393-9.

22. De Micco V, Balzano A, Wheeler EA, et al. Tyloses and gums: a review of structure, function and occurrence of vessel occlusions. IAWA J. 2016;37:186-205.

23. Choen Y, Choen S, Cantuarias-Aviles T, et al. Variations in the radial gradient of sap velocity in trunks of forest and fruit trees. Plant \& Soil. 2008;305:49-59.

24. Guyot A, Ostergaard KT, Fan J, et al. Xylem hydraulic properties in subtropical coniferous trees influence radial patterns of sap flow: implications for whole tree transpiration estimates using sap flow sensors. Trees. 2015;29:961-72.

25. Nadezhdina N, Čermák J, Ceulemans R. Radial patterns in woody stems of dominant and understory species: scaling errors associated with positioning of sensors. Tree Physiol. 2002;22:907-18.

26. Wullschleger S, King AW. Radial variation in sap velocity as a function of stem diameter and sapwood thickness in yellow-poplar trees. Tree Physiol. 2000;20:511-8.

27. Carlquist S. How wood evolves - a new synthesis. Botany. 2012;90:901-40.

28. Kedrov GB. Functioning wood. Wulfenia. 2012;19:57-95.

29. Höll W. Radial transport in rays. In: Zimmermann MH, Milburn JA, editors. Transport in plants I. Berlin: Springer; 1975. p. 432-50.

30. Roberts AG, Oparka KJ. Plasmodesmata and the control of symplastic transport. Plant Cell Environ. 2003;26:103-24.

31. Ziegler H. Use of isotopes in the study of translocation in rays. In: Isotopes and radiation in soil-plant nutrition studies. Symposium Series, IAEA, Vienna 1965; pp 361-70.

32. Gessler A, Weber P, Schneider S, et al. Bidirectional exchange of amino compounds between phloem and xylem during longdistance transport in Norway spruce trees (Picea abies [L.] Karst). J Exp Bot. 2003;54:1389-97.

33. Sauter JJ, Neumann U. The accumulation of storage materials in ray cells of poplar wood (Populus $\times$ canadensis $<$ robusta $>$ ): effect of ringing and defoliation. J Plant Physiol. 1994;143:21-6.

34. Sauter JJ, van Cleve B. Storage, mobilization and interrelations of starch, sugars, protein and fat in the ray storage tissue of poplar trees. Trees. 1994;8:297-304.

35. van Bel AJE. Xylem-phloem exchange via the rays: the undervalued route of transport. J Exp Bot. 1990;41:631-44.

36. Pfautsch S, Renard J, Tjoelker MG, et al. Phloem as capacitor: radial transfer of water into xylem of tree stems occurs via symplastic transport in ray parenchyma. Plant Physiol. 2015;167: 963-71. The study uses in-situ injections of fluorescent dye to visualize the pathway of radial flow of water from phloem into xylem, highlighting the importance of wood rays in moderating rapidly declining xylem water potential.

37. Steppe K, Cochard H, Lacointe A, et al. Could rapid diameter changes be facilitated by a variable hydraulic conductance? Plant Cell Environ. 2012;35:150-7.

38. Hölttä $\mathrm{T}$, Vesala $\mathrm{T}$, Sevanto $\mathrm{S}$, et al. Modeling xylem and phloem water flows in trees according to cohesion theory and Münch hypothesis. Trees. 2006;20:67-78.

39. Hölttä T, Mencuccini M, Nikinmaa E. Linking phloem function to structure: analysis with a coupled xylem-phloem transport model. J Theor Biol. 2009;259:325-37.

40. Pfautsch S, Hölttä T, Mencuccini M. Hydraulic functioning of tree stems - fusing ray anatomy, radial transfer and capacitance. Tree Physiol. 2015;35:706-22. 
41. De Schepper V, De Swaef T, Bauweraets I, et al. Phloem transport: a review of mechanisms and controls. J Exp Bot. 2013;64:4839-50.

42. van Bel AJE, Patrick JW, Thompson GA et al. Phloem: the integrative avenue for resource distribution, signalling and defence. Frontiers in Plant Science 2014; $352 \mathrm{p}$.

43. Raven JA. Long-term functioning of enucleate sieve elements: possible mechanisms of damage avoidance and damage repair. Plant Cell Environ. 1991;14:139-46.

44. Lucas WJ, Groover A, Lichtenberger R, et al. The plant vascular system: evolution, development and functions. J Integr Plant Biol. 2013;55:294-388.

45. van Bel AJE. The phloem, a miracle of ingenuity. Plant Cell Environ. 2003;26:125-49.

46. van Bel AJE. Transport phloem: low profile, high impact. Plant Physiol. 2003;131:1509-10.

47.• Chan T, Hölttä T, Berninger F, et al. Separating water-potential induced swelling and shrinking from measured radial stem variations reveals a cambial growth and osmotic concentration signal. Plant Cell and Environment. 2016;39:233-44. Chan and colleagues were able to separate irreversible growth from reversible, hydraulically induced expansion and contraction of stems. Diurnal and seasonal dynamics of stem tissues were resolved against changes in environmental variables.

48. Cocozza C, Marino G, Giovanelli A, et al. Simultaneous measurements of stem radius variation and sap flux density reveal synchronisation of water storage and transpiration dynamics in olive trees. Ecohydrology. 2015;8:33-45.

49. Zweifel R, Haeni M, Buchmann N, et al. Are trees able to grow in periods of stem shrinkage? New Phytol. 2016. doi:10.1111/nph.13995.

50. Zweifel R, Drew DM, Schweingruber F, et al. Xylem as the main origin of stem radius changes in Eucalyptus. Funct Plant Biol. 2014;41:520-34.

51. Carlquist S. Successive cambia revisited: ontogeny, histology, diversity, and functional significance. The Journal of the Torrey Botanical Society. 2007;134:301-32.

52. Robert EMR, Schmitz N, Boeren I, et al. Successive cambia: a developmental oddity or an adaptive structure? PLoS One. 2011;6:e16558

53. Robert E, Schmitz N, Copini P, et al. Visualization of the stem water content of two genera with secondary phloem produced by successive cambia through Magnetic Resonance Imaging (MRI). Journal of Plant Hydraulics. 2014;1:e006 .Retrieved from http://jplanthydro.org/articleub/view/32

54. Hill AE, Shachar-Hill B, Shachar-Hill Y. What are aquaporins for? J Membr Biol. 2004;197:1-32.

55. Buckley T. The control of stomata by water balance. Plant Cell Environ. 2005;168:275-92.

56. Pfautsch S, Harbusch M, Wesolowski A, et al. Climate determines vascular traits in the ecologically diverse genus Eucalyptus. Ecol Lett. 2016;19:340-9.

57. Tyree MT, Sperry JS. Vulnerability of xylem to cavitation and embolism. Annu Rev Plant Biol. 1989;40:19-36.

58. Davis SD, Sperry JS, Hacke UG. The relationship between xylem conduit diameter and cavitation caused by freezing. Am J Bot. 1999;86:1367-72.

59. Cobb AR, Choat B, Holbrook NM. Dynamics of freeze-thaw embolism in Smilax rotundifolia (Smilacaceae). Am J Bot. 2007;94:640-9.

60. Li S, Lens F, Espino S, et al. Intervessel pit membrane thickness as a key determinant of embolism resistance in angiosperm xylem. IAWA J. 2016;37:152-71. The most comprehensive work to date that assesses the effect of pit membrane thickness on embolism resistance in woody angiosperm species, also highlighting the importance of sample treatment prior to analyses.

61. Tyree MT, Zimmermann MH. Xylem structure and the ascent of sap. Berlin: Springer; 2002.
62. Murray CD. The physiological principle of minimum work. 1. The vascular system and the cost of blood volume. Proceedings of the National Academy of Sciences of the USA. 1926;12:207-14.

63. Weitz JS, Ogle K, Horn HS. Ontogenetically stable hydraulic design in woody plants. Funct Ecol. 2006;20:191-9.

64. Adams III WW, Stewart JJ, Cohu CM, et al. Habitat temperature and precipitation of Arabidopsis thaliana ecotypes determine the response of foliar vasculature, photosynthesis, and transpiration to growth temperature. Front Plant Sci. 2016. doi:10.3389/fpls.2016.01026.

65. Anfodillo T, Carraro V, Carrer M, et al. Convergent tapering of xylem conduits in different woody species. New Phytol. 2006;169:279-90.

66. Petit G, Pfautsch S, Anfodillo T, et al. The challenge of tree height in Eucalyptus regnans: when xylem tapering overcomes hydraulic resistance. New Phytol. 2010;187:1146-53.

67. West GB, Brown JH, Enquist BJ. A general model for the origin of allometric scaling laws in biology. Science. 1997;276:122-6.

68. Mencuccini M, Hölttä T, Petit G, et al. Sanio's law revisited: size dependent changes in the xylem architecture of trees. Ecol Lett. 2007;10:1084-93.

69. Petit G, Crivellaro A. Comparative axial widening of phloem and xylem conduits in small woody plants. Trees. 2014;28:915-21.

70. Reich PB. The world-wide 'fast-slow' plant economics spectrum: a traits manifesto. J Ecol. 2014;102:275-301.

71. Manzoni S, Vico G, Katul G, et al. Hydraulic limits on maximum plant transpiration and the emergence of the safety-efficiency trade-off. New Phytol. 2013;198:169-78.

72. Jansen S, Choat B, Pletseres A. Morphological variation of intervessel pit membranes and implications to xylem function in angiosperms. Am J Bot. 2009;96:409-19.

73. Lens F, Sperry JS, Christman MA, et al. Testing hypotheses that link wood anatomy to cavitation resistance and hydraulic conductivity in the genus Acer. New Phytol. 2011;180:709-23.

74. Wheeler JK, Sperry JS, Hacke UG, et al. Inter-vessel pitting and cavitation in woody Rosaceae and other vesselled plants: a basis for a safety versus efficiency trade-off in xylem transport. Plant Cell Environ. 2005;28:800-12.

75. Choat B, Brodie TW, Cobb AR, et al. Direct measurement of intervessel pit membrane hydraulic resistance in two angiosperm tree species. Am J Bot. 2006;93:933-1000.

76. Sperry JS, Donnelly JR, Tyree MT. A method for measuring hydraulic conductivity and embolism in xylem. Plant Cell Environ. 1988;11:35-40.

77. Pittermann J. The evolution of water transport in plants: an integrated approach. Geobiology. 2010;8:122-39.

78. Choat B, Ball M, Luly J, et al. Pit membrane porosity and water stress-induced cavitation in four co-existing dry rainforest tree species. Plant Physiol. 2003;131:41-8.

79. Choat B, Pittermann J. New insights into bordered pit structure and cavitation resistance in angiosperms and conifers. New Phytol. 2009;182:557-60.

80. Pittermann J, Sperry JS, Hacke UG, et al. Torus-margo pits help conifers compete with angiosperms. Science. 2005;310:1924.

81. Dixon HD, Joly J. On the ascent of sap. Philos Trans R Soc Lond B. $1895 ; 186: 563-76$.

82. Holbrook NM, Burns MJ, Field CB. Negative xylem pressures in plants: a test of the balancing pressure technique. Science. 1995;270:1193-4.

83. Scholander PF, Hammel HT, Bradstreet ED, et al. Sap pressure in vascular plants. Science. 1965;148:339-46.

84. Stroock AD, Pagay VV, Zwieniecki MA, et al. The physiochemical hydrodynamics of vascular plants. Annual Review of Fluid Dynamics. 2014;46:615-42.

85. Choat B, Jansen J, Brodribb T, et al. Global convergence in the vulnerability of forests to drought. Nature. 2012;491:752-5. 
86. Mayr S, Gruber A, Bauer H. Repeated freeze-thaw cycles induce embolism in drought stressed conifers (Norway spruce, stone pine). Planta. 2003;217:436-41.

87. Stuart SA, Choat B, Martin KC, et al. The role of freezing in setting the latitudinal limits of mangrove forests. New Phytol. 2007; 173:576-83.

88. Anderegg WRL, Klein T, Barlett M, et al. Meta-analysis reveals that hydraulic traits explain cross-species patterns of droughtinduced tree mortality across the globe. Proceedings of the National Academy of Sciences of the USA. 2016;113:5024-9.

89. Brodribb $\mathrm{T}, \mathrm{Cochard} \mathrm{H}$. Hydraulic failure defines the recovery of point of death in water-stressed conifers. Plant Physiol. 2009;149:575-84.

90. Urli M, Porté AJ, Cochard H, et al. Xylem embolism threshold for catastrophic hydraulic failure in angiosperm trees. Tree Physiol. 2013;33:672-83.

91. Pittermann J, Sperry JS. Analysis of freeze-thaw embolism in conifers. The interaction between cavitation pressure and tracheid size. Plant Physiol. 2006;140:374-82.

92. Sevanto S, Holbrook NM, Ball M. Freeze/thaw-induced embolism: probability of critical bubble formation depends on speed of ice formation. Front Plant Sci. 2012. doi:10.3389/fpls.2012.00107.

93. Pittermann J, Sperry J. Tracheid diameter is the key trait determining the extent of freezing-induced embolism in conifers. Tree Physiol. 2003;23:907-14.

94. Mayr S, Sperry JS. Freeze-thaw-induced embolism in Pinus contorta: centrifuge experiments validate the "thaw-expansion hypothesis' but conflict with ultrasonic emission data. New Phytol. 2010;185:1016-24.

95. Ball MC, Canny MJ, Huang CX, et al. Freezethaw-induced embolism depends on nadir temperature: the heterogeneous hydration hypothesis. Plant, Cell and Environment. 2006;29:729-45.

96. Feild TS, Brodribb T. Stem water transport and freeze-thaw xylem embolism in conifers and angiosperms in a Tasmanian treeline heath. Oecologia. 2001;127:314-20.

97. Choat B, Medek DE, Stuart SA, et al. Xylem traits mediate a tradeoff between resistance to freeze-thaw-induced embolism and photosynthetic capacity in overwintering evergreens. New Phytol. 2011;191:996-1005.

98. Utsumi Y, Sano Y, Ohtani J, et al. Seasonal changes in the distribution of water in the outer growth rings of Fraxinus mandshurica var. japonica: a study by cryo-scanning electron microscopy. IAWA J. 1996;17:113-24.

99. Zimmermann MH, Brown CL. Trees: structure and function. Berlin: Springer; 1971.

100. Cochard H, Cruiziat P, Tyree MT. Use of positive pressures to establish vulnerability curves further support for the air-seeding hypothesis and implications for pressure-volume analysis. Plant Physiol. 1992;100:205-9.

101. Tyree MT, Davis SD, Cochard H. Biophysical perspectives of xylem evolution: is there a tradeoff of hydraulic efficiency for vulnerability to dysfunction? IAWA J. 1994;15:335-60.

102. Brodersen $\mathrm{CR}, \mathrm{McEl}$ lrone $\mathrm{AJ}$, Choat $\mathrm{B}$, et al. In vivo visualizations of drought-induced embolism spread in Vitis vinifera. Plant Physiol. 2013;161:1820-9.

103. Choat B, Badel E, Burlett R, et al. Noninvasive measurement of vulnerability to drought-induced embolism by X-ray microtomography. Plant Physiol. 2015;170:273-82.

104. Cochard H, Badel E, Herbette S, et al. Methods for measuring plant vulnerability to cavitation: a critical review. J Exp Bot. 2013. doi:10.1093/jxb/ert193.

105. Cochard H, Delzon S, Badel E. X-ray microtomography (micro$\mathrm{CT}$ ): a reference technology for high-resolution quantification of xylem embolism in trees. Plant Cell Environ. 2015;38:201-6.

106. Choat B, Badel E, Burlett R, et al. Non-invasive measurement of vulnerability to drought induced embolism by X-ray microtomography. Plant Physiol. 2015. doi:10.1104/pp.15.00732.
107. Clearwater MJ, Clark CJ. In vivo magnetic resonance imaging of xylem vessel contents in woody lianas. Plant Cell Environ. 2003;26:1205-14.

108. Holbrook NM, Ahrens ET, Burns MJ, et al. In vivo observation of cavitation and embolism repair using magnetic resonance imaging. Plant Physiol. 2001;126:27-31.

109. Bouche PS, Delzon S, Choat B, et al. Are needles of Pinus pinaster more vulnerable to xylem embolism than branches? New insights from X-ray computed tomography. Plant Cell Environ. 2016;39:860-70.

110. Brodersen CR, McElrone AJ, Choat B, et al. The dynamics of embolism repair in xylem: in vivo visualizations using high-resolution computed tomography. Plant Physiol. 2010;154:1088-95.

111. Knipfer T, Eustis A, Brodersen C, et al. Grapevine species from varied native habitats exhibit differences in embolism formation/ repair associated with leaf gas exchange and root pressure. Plant Cell Environ. 2015;38:1503-13.

112. Windt CW, Soltner H, Dusschoten D, et al. A portable Halbach magnet that can be opened and closed without force: the NMRCUFF. J Magn Reson. 2011;208:27-33.

113. Windt CW, Blümler P. A portable NMR sensor to measure dynamic changes in the amount of water in living stems or fruit and its potential to measure sap flow. Tree Physiol. 2015;35:366-75.

114. Fiorani F, Rascher U, Jahnke S, et al. Imaging plant dynamics in heterogenic environments. Curr Opin Biotechnol. 2012;23:227-35.

115. McDowell N, Pockman WT, Allen CD, et al. Mechanisms of plant survival and mortality during drought: why do some plants survive while others succumb to drought? New Phytol. 2008;178:719-39.

116. McDowell N, Fisher RA, Xu C, et al. Evaluating theories of drought-induced vegetation mortality using a multimodelexperimental framework. New Phytol. 2013;200:304-21.

117. Anderegg WRL, Anderegg LDL, Berry JA, et al. Loss of wholetree hydraulic conductance during severe drought and multi-year forest die-off. Oecologia. 2014;175:11-23.

118. Anderegg WRL, Flint A, Huang C, et al. Tree mortality predicted from drought-induced vascular damage. Nat Geosci. 2015;8:367-71.

119. Hentschel R, Rosner S, Kayler ZE, et al. Norway spruce physiological and anatomical predisposition to die-back. Forest Ecology \& Management. 2014;322:27-36.

120. Mitchell PJ, O'Grady AP, Tissue DT, et al. Co-ordination of growth, gas exchange and hydraulics define the carbon safety margin in tree species with contrasting drought strategies. Tree Physiol. 2014;34:443-58.

121. Sevanto S, McDowell NG, Dickman LT, et al. How do trees die? A test of the hydraulic failure and carbon starvation hypotheses. Plant Cell Environ. 2014;37:153-61.

122. Camarero JJ, Gazol A, Sangüesa-Barreda G, et al. To die or not to die: early warnings of tree dieback in response to a severe drought. J Ecol. 2015;103:44-57.

123. Breshears DD, Cobb NS, Rich PM, et al. Regional vegetation dieoff in response to global-change-type drought. Proceedings of the National Academy of Sciences of the USA. 2005;102:15144-8.

124. Anderegg WRL, Kane JM, Anderegg LDL. Consequences of widespread tree mortality triggered by drought and temperature stress. Nat Clim Chang. 2012;3:30-6.

125. McDowell N, Williams AP, Xu C, et al. Multi-scale predictions of massive conifer mortality due to chronic temperature rise. Nat Clim Chang. 2016;6:295-300.

126. Millar CI, Stephenson NL. Temperate forest health in an era of emerging megadisturbance. Science. 2015;349:823-6.

127. Allen CD, Macalady AK, Chenchouni H, et al. A global overview of drought and heat-induced tree mortality reveals emerging climate change risks for forests. Forest Ecology \& Management. 2010;259:660-84.

128. Steinkamp J, Hickler T. Is drought-induced forest dieback globally increasing? J Ecol. 2015;103:31-43. 
129. Skelly JM, Innes JL. Waldsterben and the forests of central Europe and eastern North America: fantasy or reality? Plant Dis. 1994;78:1021-32.

130. Delzon S, Cochard H. Recent advances in tree hydraulics highlight the ecological significance of the hydraulic safety margin. New Phytol. 2014;203:355-8.

131. Anderegg LDL, Anderegg WRL, Berry JA. Not all droughts are created equal: translating meteorological drought into woody plant mortality. Tree Physiol. 2013;33:672-83. An overdue reminder that only a certain sequence of processes related to water limitation - including feedback and feed-forward mechanisms will result in plant death.

132.• Martínez-Vilalta J, Poyatos R, Aguadé D, et al. A new look at water transport regulation in plants. New Phytol. 2014;204:10515. The authors develop and test a novel framework for water use strategies of plants based on predawn and midday water potentials of leaves.

133. Matusik G, Ruthrof KX, Fontaine JB, et al. Eucalyptus forest shows low structural resistance and resilience to climate changetype drought. J Veg Sci. 2016;27:493-503.

134. Ciais P, Reichstein M, Viovy N, et al. Europe-wide reduction in primary productivity caused by the heat and drought in 2003 . Nature. 2005;437:529-33.

135.• Pfautsch S, Adams MA. Water flux of Eucalyptus regnans: defying summer drought and a record heatwave in 2009. Oecologia. 2013;172:317-26. The study is a rare example how water use of mature trees is altered by drought and a heatwave. It highlights the importance of stored water to mitigate hydraulic stress.

136. Skelton RP, West AG, Dawson TE. Predicting plant vulnerability to drought in biodiverse regions using functional traits. Proceedings of the National Academy of Sciences of the USA. 2015;112:5744-9.

137. Gleason SM, Blackman CJ, Cook AM, et al. Whole-plant capacitance, embolism resistance and slow transpiration rates all contribute to longer desiccation times in woody angiosperms from arid and wet habitats. Tree Physiol. 2014;34:275-84.

138. Secchi S, Zwieniecki MA. Accumulation of sugars in the xylem apoplast observed under water stress conditions is controlled by xylem pH. Plant Cell Environ. 2016. doi:10.1111/pce.12767.

139. Hacke UG, Laur J. Xylem refilling - a question of sugar transporters and pH? Plant Cell Environ. 2016. doi:10.1111/pce.12784.

140. Hölttä T, Kruppa M, Nikinmaa E. Scaling of xylem and phloem transport capacity and resource usage with tree size. Front Plant Sci. 2013. doi:10.3389/fpls.2013.00496.

141. Aspinwall MJ, Loik ME, de Dios V R, et al. Utilizing intraspecific variation in phenotypic plasticity to bolster agricultural and forest productivity under climate change. Plant, Cell \& Environment. 2015;38:1552-64.

142. Torres-Ruiz JM, Diaz-Espejo A, Perez-Martin A, et al. Role of hydraulic and chemical signals in leaves, stems and roots in the stomatal behaviour of olive trees under water stress and recovery conditions. Tree Physiol. 2015;35:415-24.

143. Sperry SJ, Hacke UG, Pittermann J. Size and function of conifer tracheids and angiosperm vessels. Am J Bot. 2006;93:1490-500.

144. Carlquist S. Caryophyllales: a key group for understanding wood anatomy character states and their evolution. Bot J Linn Soc. 2010;164:342-93.

145. Liu J, Noshiro S. Lack of latitudinal trends in wood anatomy of Dodonaea viscosa (Sapindaceae), a species with a worldwide distribution. Am J Bot. 2003;90:532-9.

146. Lens F, Luteyn JL, Smets E, et al. Ecological trends in the wood anatomy of accinioideae (Ericaceae sl). Flora. 2004;199:309-19.

147. Noshiro S, Suzuki M. Ecological wood anatomy of Nepalese Rhododendron (Ericaceae). 2. Intraspecific variation. J Plant Res. 1995; 108:217-33.

148. Rossi S, Anfodillo T, Čufar K, et al. Pattern of xylem phenology in conifers of cold ecosystems at the Northern Hemisphere. Glob Chang Biol. 2016. doi:10.1111/gcb.13317.

149. Baas P. Ecological patterns in xylem anatomy. In: Givnish T, editor. On the economy of plant form and function. Cambridge: Cambridge University Press; 1986.

150. Baas P, Battipaglia G, De Micco V, et al. Wood structure in plant biology and ecology. IAWA J. 2013;34:331-509.

151. Beeckman H. 2016. Wood anatomy and trait-based ecology. IAWA J. 2016;37:127-51.

152. Carlquist S. Comparative wood anatomy. Systematic, ecological, and evolutionary aspects of dicotyledon wood. 2nd ed. Berlin: Springer; 2001.

153. Carlquist S, Hoekman DA. Ecological wood anatomy of the southern Californian flora. IAWA Bulletin. 1985;6:319-47.

154. Hacke UG (ed.). Functional and ecological xylem anatomy. Springer International Publishing Switzerland 2015, 288p.

155. Chave J, Coomes D, Jansen S, et al. Towards a worldwide wood economics spectrum. Ecol Lett. 2009;12:351-66.

156. Zanne AE, Westoby M, Falster DS, et al. Angiosperm wood structure: global patterns in vessel anatomy and their relation to wood density and potential conductivity. Am J Bot. 2010;97:207-15.

157. Kattge J, Díaz S, Lavorel S, et al. TRY — a global database of plant traits. Glob Chang Biol. 2011;17:2905-35.

158. Wheeler EA. InsideWood - a web resource for hardwood anatomy. IAWA J. 2011;32:199-211. 